\title{
Advances in Understanding Parosmia: An fMRI Study
}

\author{
Emilia lannillia Donald A. Leopold ${ }^{b}$ David E. Hornung ${ }^{c}$ \\ Thomas Hummel ${ }^{\mathrm{a}}$ \\ a Smell and Taste Clinic, Department of Otorhinolaryngology, TU Dresden, Dresden, \\ Germany; ${ }^{b}$ Department of Otolaryngology, University of Nebraska, Omaha, NE, USA; \\ 'Department of Biology, St. Lawrence University, Canton, OH, USA
}

\section{Keywords}

Olfaction $\cdot$ Smell $\cdot$ Parosmia $\cdot$ Quality of life $\cdot$ Functional MRI

\begin{abstract}
Introduction: A number of patients with a diminished sense of smell also can suffer from parosmia. These patients with such a qualitative smell disorder are often more severely affected than patients exhibiting only a quantitative smell disorder. Qualitative smell disorders have heretofore been poorly investigated. The focus of the present study was, using functional MRI, to compare the central processing of olfactory stimulation in patients with qualitative smell disorders. Material and Methods: A total of 23 patients were investigated, 12 hyposmic patients without parosmia (HYP group) and 11 hyposmic patients with parosmia (PAR group). Both groups were matched with regard to sex and age. The olfactory smells used were peach and coffee odors. Results: The two groups exhibited different patterns of activation. In HYP patients a stronger activation was observed in the medial orbitofrontal cortex, anterior cingulate cortex, and parahippocampal gyrus, whereas in the PAR group stronger activation in the thalamus and putamen was seen. Discussion: These results are consistent with the hypothesis that there are specific patterns in the central processing of olfactory stimuli which differ in hyposmic patients with and without parosmia.

(C) 2019 S. Karger AG, Basel
\end{abstract}

\section{Introduction}

Alterations of the sense of smell can occur quantitatively and/or qualitatively [1]. Olfactory disorders are categorized as hyperosmia, normosmia, hyposmia, or anosmia [2]. These deficits can be described relatively easily using quantitative tests of olfactory function, e.g., the "Sniffin' Sticks" [3]. Qualitative changes in olfaction (parosmia, phantosmia) are also 
lannilli et al.: Parosmia

reported frequently; in fact, at first referral about one third of patients with olfactory dysfunction complain of qualitative olfactory dysfunction, albeit to various degrees [4-6]. Parosmias are defined as qualitative dysfunction in the presence of an odor (i.e., distorted perception of an odor stimulus), and phantosmias as qualitative dysfunction in the absence of an odor (i.e., an odor is perceived without concurrent stimulus, an "olfactory hallucination") $[2,7]$. An objective measure of qualitative olfactory dysfunction is so far not available.

The cause of qualitative olfactory dysfunction is unclear. One explanation relates to the periphery of the olfactory system where partial dysfunction of olfactory receptor neurons leads to the inability to form a typical, odor-specific pattern of activation in the olfactory bulb $[8,9]$. Another hypothesis relates to the idea that parosmias are the result of an aberrant central-nervous processing of odors, e.g., in the olfactory bulb [10,11] and/or integrative/ interpretative centers in the olfactory-eloquent brain structures [12]. The decreased olfactory bulb volume of patients with parosmia may indicate that there may be a decreased number of bulb interneurons, and therefore, a decreased lateral inhibition [13], that may allow olfactory activation to produce an irregular pattern, which then results in an altered olfactory perception [6]. The aim of the present study was to further investigate possible differences in the central processing of hyposmic patients with parosmia compared to hyposmic patients without parosmia.

\section{Materials and Methods}

A total of 23 subjects participated in the study, divided into two groups: hyposmic patients with parosmia (PAR group) and hyposmic patients without parosmia (HYP group).

The classification of a patient into the PAR or HYP group was determined by her/his response to questions during the history about changes in odor quality perception as described in the questionnaire by Landis et al. [14]: "the biggest problem is not that I do not or weakly perceive odors, but that they smell different than they should" and "odors which are pleasant to other people are unpleasant for me."

The PAR group consisted of 7 women and 4 men (mean age: 61.2 years, SD: 17.2) whereas the HYP group consisted of 8 women and 4 men (mean age: 56.4 years, SD: 17.1). Regarding the PAR patients, their olfactory loss was likely related to an infection ( 2 men and 5 women) or head trauma ( 2 men and 2 women); in HYP patients the olfactory loss was likely related to an infection ( 1 man and 5 women) or head trauma ( 3 men and 3 women). Patients in neither group reported the presence of phantom smells which was examined through a question similar to "I always have a bad odor in my nose, regardless if any odor source is present" [14].

Before entering the study, a thorough medical history was taken and a complete head and neck examination including nasal endoscopy was completed. The examination was conducted to rule out major intranasal pathologies [15].

Psychophysical Tests of Olfactory Function

All subjects underwent extensive tests of olfactory function. Olfactory function was measured with the "Sniffin' Sticks" olfactory test kit [16], where odorants are presented in commercially available felt-tip pens (Burghart, Wedel, Germany). The kit consists of separate tests for phenylethyl alcohol (PEA) odor thresholds, odor discrimination, and identification. Results of the three subtests are presented as a composite ThresholdDiscrimination-Identification (TDI) score. Based on a multicenter investigation [17], subjects with a TDI score below 16 are considered functionally anosmic, subjects with a score between 16 and 30 are considered hyposmic, and those with a score above 30 are identified normosmic.

\section{Functional MRI}

Each subject participated in four sessions with two common "food-like" olfactory stimuli (peach- and coffee-like odor) presented in a randomized order unilaterally to the right and then the left nostril. This resulted in 4 conditions ( 2 odors $\times 2$ sides of stimulation). The 4 conditions were meant to make the paradigm more interesting to the participants. In addition, by collapsing all conditions together for later analysis the power of the results was strengthened. There was no intention to analyze the 4 conditions separately. 


\begin{tabular}{l|l}
\hline ORL 2019;81:185-192 \\
\hline DOI: 10.1159/000500558 & $\begin{array}{l}\text { @ 2019 S. Karger AG, Basel } \\
\text { www.karger.com/orl }\end{array}$ \\
\hline
\end{tabular}

lannilli et al.: Parosmia
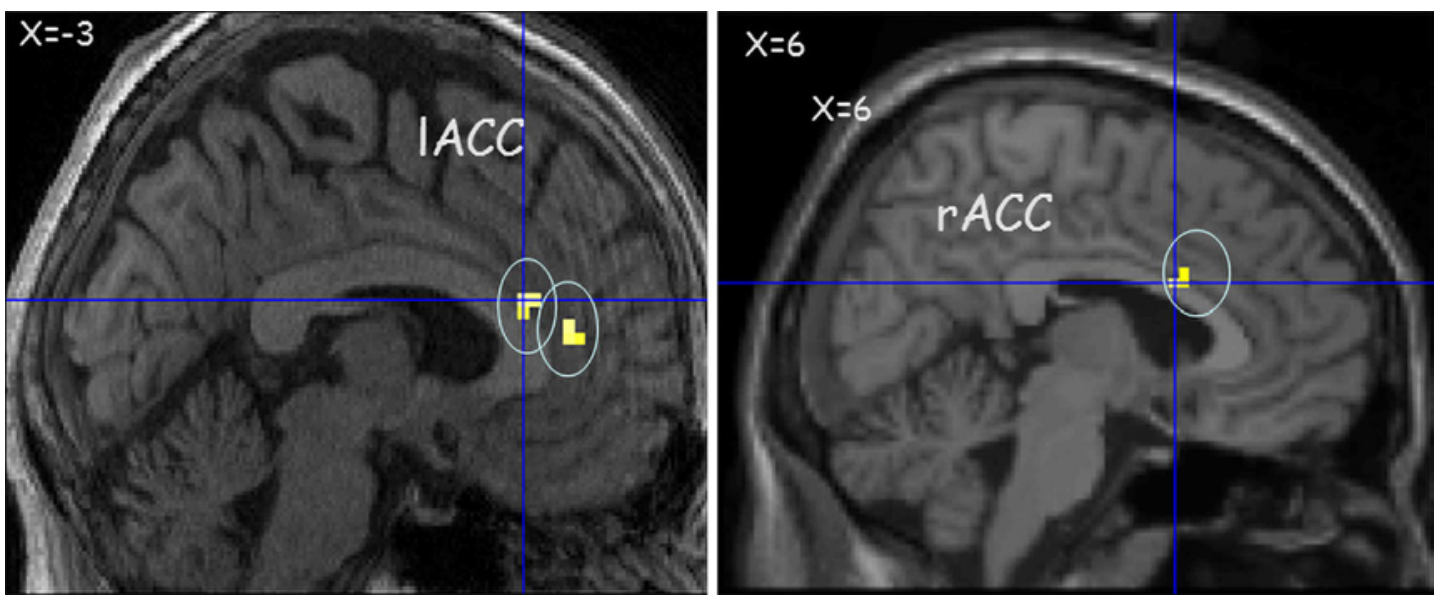

Fig. 1. Activations in the left (l) and right ( $\mathrm{r}$ ) anterior cingulate cortex (ACC) following the contrast HYPosmia > PARosmia with data pooled odors (peach and coffee) projected on the sagittal planes $(x=-3)$ and $(x=-6)$ of a normalized brain to the MNI (Montreal Neurological Institute) coordinates. Statistical threshold $p_{\text {uncorr }}<$ 0.003 , cluster level 3 .

Odors were presented intranasally (inner diameter of the Teflon ${ }^{\mathrm{TM}}$ tubing: $4 \mathrm{~mm}$ ). To avoid mechanical stimulation odor pulses were embedded in a constant flow of odorless, humidified air (2 L/min). During the stimulation periods ( $\mathrm{ON}$ - see below) stimulus pulses had a duration of $1 \mathrm{~s}$; the interval between stimuli was $2 \mathrm{~s}$.

For stimulus presentation a block design was used. ON and OFF blocks of $20 \mathrm{~s}$ each were repeated 6 times per session; each session lasted $4 \mathrm{~min}$. In each session the participants received 8 scans during the 20 -s-ON block and 8 during the 20-s-OFF block. The sequence of sessions was randomized across participants.

We used a 1.5T scanner (SONATA-MR; Siemens, Erlangen, Germany) for functional MRI (fMRI) data acquisition. For functional data 96 volumes per session were acquired by means of a 26 axial-slice matrix 2D SE/EP sequence (TR: 2,630 ms/TE: $45 \mathrm{~ms}$, matrix $=64 \times 64$, voxel size $3 \times 3 \times 3.75 \mathrm{~mm}^{3}$ ). Following fMRI measurements, T1-weighted images were acquired by using a 3D IR/GR sequence (TR: 2,180 ms/TE: 3.39 $\mathrm{ms}$ ) to anatomically localize the activated areas.

Data analysis was performed with SPM 5 software (Statistical Parametric Mapping; Wellcome Department of Imaging Neuroscience, Institute of Neurology, University College London, UK), implemented in MATLAB R2007b (MathWorks Inc., Natick, MA, USA), following spatial pre-processing with the same software (spatial filtering: high pass filter $128 \mathrm{~Hz}$, normalization using segmentation procedure, smoothing by means of $9 \times 9 \times 9$ FWHM). Coordinates of the activation are presented according to Talairach and Tournoux [18]. Analyses were based on $t$ tests with a cluster level of 3 and $p<0.003$ (uncorrected). For other statistical analyses we used the program package SPSS (version 25; SPSS, Chicago, IL, USA).

\section{Results}

\section{Psychophysical Tests of Olfactory Function}

Olfactory testing revealed no significant differences between the two groups regarding TDI scores. Thresholds for PEA were identified at a mean score of 1.92 (standard error of means [SEM]: 1.67) in HYP patients and at 1.56 (SEM: 0.64) in PAR patients. In the discrimination task the mean scores were at 9.58 (SEM: 2.14) and 10.42 (SEM: 2.22), respectively. When asked to correctly identify odorants, HYP patients reached on average 8.92 points (SEM: 2.06) and PAR patients 8.67 (SEM: 1.80) correct answers. Altogether, the mean TDI score in the HYP group was seen at 20.42 (SEM: 4.1) and 20.65 (SEM: 2.9) in the PAR group. 
lannilli et al.: Parosmia
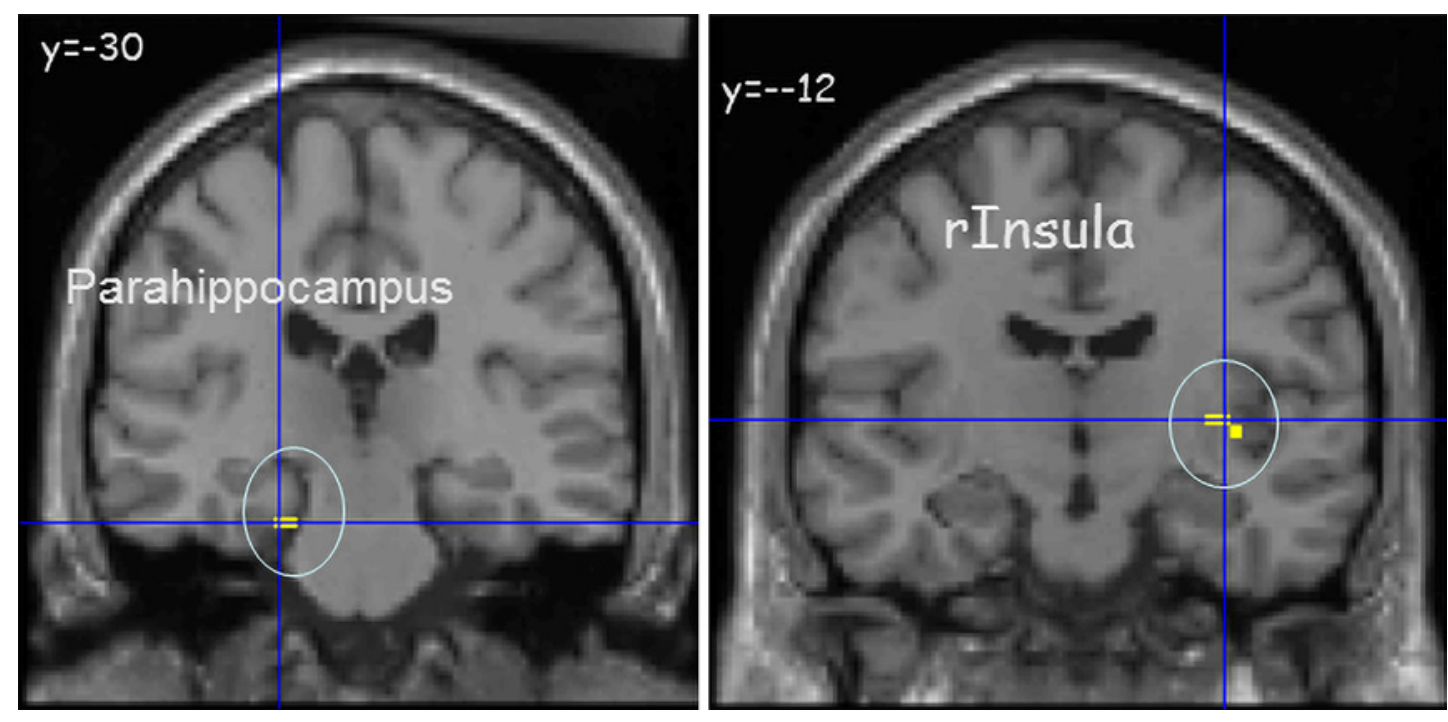

Fig. 2. Activations in the left parahippocampus and right ( $\mathrm{r}$ ) insula following the contrast HYPosmia > PARosmia with data pooled odors (peach and coffee) projected on the coronal plane $(y=-21)$ of a normalized brain to the MNI (Montreal Neurological Institute) coordinates. Statistical threshold $p_{\text {uncorr }}<0.003$, cluster level 3.

Table 1. Comparison of activation in the parahippocampal gyrus, insula, anterior cingulate cortex, and orbitofrontal cortex in groups with data pooled odors (peach and coffee)

\begin{tabular}{|c|c|c|c|c|}
\hline & \multirow[t]{2}{*}{$t$ value } & \multicolumn{3}{|c|}{ Talairach coordinates } \\
\hline & & $x$ & $y$ & $z$ \\
\hline Parahippocampal gyrus & $\begin{array}{l}4.01 \\
3.34 \\
3.33\end{array}$ & $\begin{array}{l}-18 \\
-21 \\
-15\end{array}$ & $\begin{array}{l}-33 \\
-24 \\
-30\end{array}$ & $\begin{array}{r}-6 \\
-24 \\
-21\end{array}$ \\
\hline Insula & 3.18 & 36 & -12 & 3 \\
\hline Anterior cingulate cortex & $\begin{array}{l}3.94 \\
3.93 \\
3.83\end{array}$ & $\begin{array}{r}-3 \\
-3 \\
6\end{array}$ & $\begin{array}{l}27 \\
39 \\
12\end{array}$ & $\begin{array}{l}18 \\
12 \\
24\end{array}$ \\
\hline Orbitofrontal cortex & 3.50 & 24 & 39 & -15 \\
\hline
\end{tabular}

HYP patients versus PAR patients. $p_{\text {uncorr }}<0.003$, cluster level 3 .

\section{Functional MRI}

After collapsing all conditions ( 2 odors plus 2 sides of stimulation) we compared the ON contrasts of the HYP group with the ON contrasts of the PAR group and performed a small volume correction for olfactory processing areas (orbitofrontal cortex, insula, limbic system, and cerebellum). This contrast revealed different activation patterns in the respective groups. In HYP patients we found significantly increased activation in the right orbitofrontal cortex $(24 / 39 /-15 ; t=3.50)$, left anterior cingulate cortex $(-3 / 27 / 18 ; t=3.94$ and $-3 / 39 / 12$; $t=3.93$ ) (Fig. 1), and left parahippocampal gyrus (-18/-33/-6; $t=4.01 ;-21 /-24 /-24 ; t=$ 3.34 , and $-15 /-30 /-21 ; t=3.33$ ) compared to the PAR group (Table $1 ;$ Fig. 2 ). There was also stronger activation in the right insula in HYP patients $(36 /-12 / 3 ; t=3.18)$. In contrast, we saw increased activation in PAR patients in the left thalamus $(-23 /-21 / 12 ; t=3.46)$ (Fig. 3) and in the right putamen $(30 / 0 / 3, t=3.46)$ (Table 2; Fig. 4). 


\begin{tabular}{l|l}
\hline ORL 2019;81:185-192 \\
\hline DOI: 10.1159/000500558 & $\begin{array}{l}\text { @ 2019 S. Karger AG, Basel } \\
\text { www.karger.com/orl }\end{array}$ \\
\hline
\end{tabular}

Fig. 3. Activation in the left (l) thalamus following the contrast PARosmia > HYPosmia with data pooled odors (peach and coffee) projected on the coronal plane $(y=$ -21 ) of a normalized brain to the MNI (Montreal Neurological Institute) coordinates. Statistical threshold $\mathrm{p}_{\text {uncorr }}<0.003$, cluster level 3.

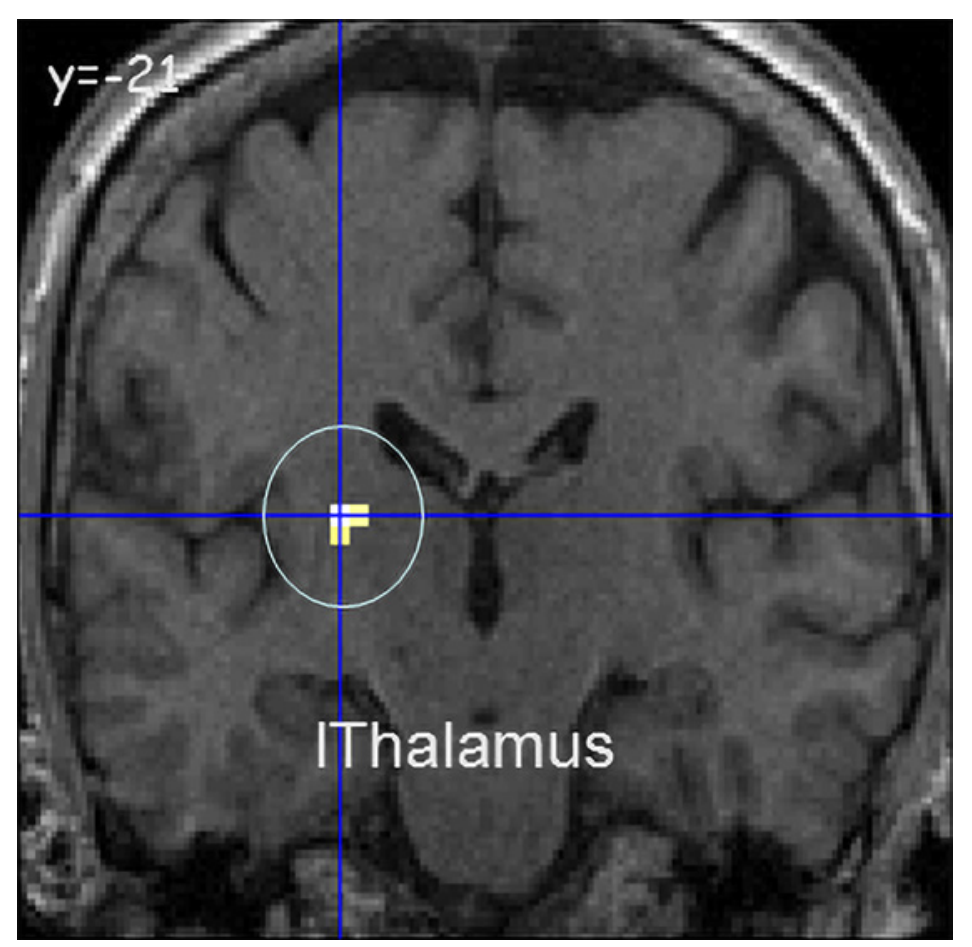

\section{Discussion}

The major finding of the present study was that, in comparison to PAR patients, HYP patients activated areas which are typically found after olfactory stimulation, namely the parahippocampal gyrus, insula, anterior cingulate cortex, and orbitofrontal cortex. All these areas are typically reported in relation to associations activated as a consequence of the odorous sensation, for example [19]. This pattern of activation supports the idea that HYP patients have regular cortical processing of olfactory stimuli, albeit at a somewhat lower level [20].

In contrast, PAR patients exhibit stronger activation in the thalamus, known to be related to directed attention in relation to the sense of smell [21], and the putamen. The putamen is a structure that has been implicated in the perception of contempt and disgust [22, 23]; damage to the putamen and insula apparently compromises a patient's ability to recognize signals of disgust [24]. It contains neurons that are active in phases preparatory to motor acts [25] and has been shown to be active in conditions in which cognitive planning is required to trigger a motor act $[26,27]$. The putamen is also involved in dopamine reward responses [28]. Finally, results of a recent study aimed to assess olfactory cortical networks (OCN) showed that the putamen is connected with both the functional OCN, detected with a statistical approach with neuroimaging techniques, and the structural OCN, suggesting an important role of such structures in the processing of olfactory stimuli [29]. An increase of activity in the putamen in the pathological condition of parosmia suggests that this area may be (at least in part) responsible for the distorted perception. These differences between the two groups seem to indicate that the odorous stimuli had a higher degree of salience for PAR patients. For PAR patients these odors were distorted, leading to unpleasant sensations. Unpleasant odors are typically more meaningful than pleasant sensations [30-32], which normally do not signal a potential threat. These unpleasant sensations would then produce more activation in PAR patients than the more neutral odorous sensations experienced in HYP patients. Along the same line of thought, it is also fitting that PAR patients, and not HYP patients, exhibit stronger 


\begin{tabular}{l|l}
\hline ORL 2019;81:185-192 \\
\hline DOI: 10.1159/000500558 & $\begin{array}{l}\text { (c) 2019 S. Karger AG, Basel } \\
\text { www.karger.com/orl }\end{array}$ \\
\hline
\end{tabular}

Fig. 4. Activation in the right (r) putamen following the contrast PARosmia > HYPosmia with data pooled odors (peach and coffee) projected on the axial plane $(z=$ 3) of a normalized brain to the MNI (Montreal Neurological Institute) coordinates. Statistical threshold $p_{\text {uncorr }}<0.003$, cluster level 3.

Table 2. Comparison of activation in the putamen and thalamus in groups with data pooled odors (peach and coffee)

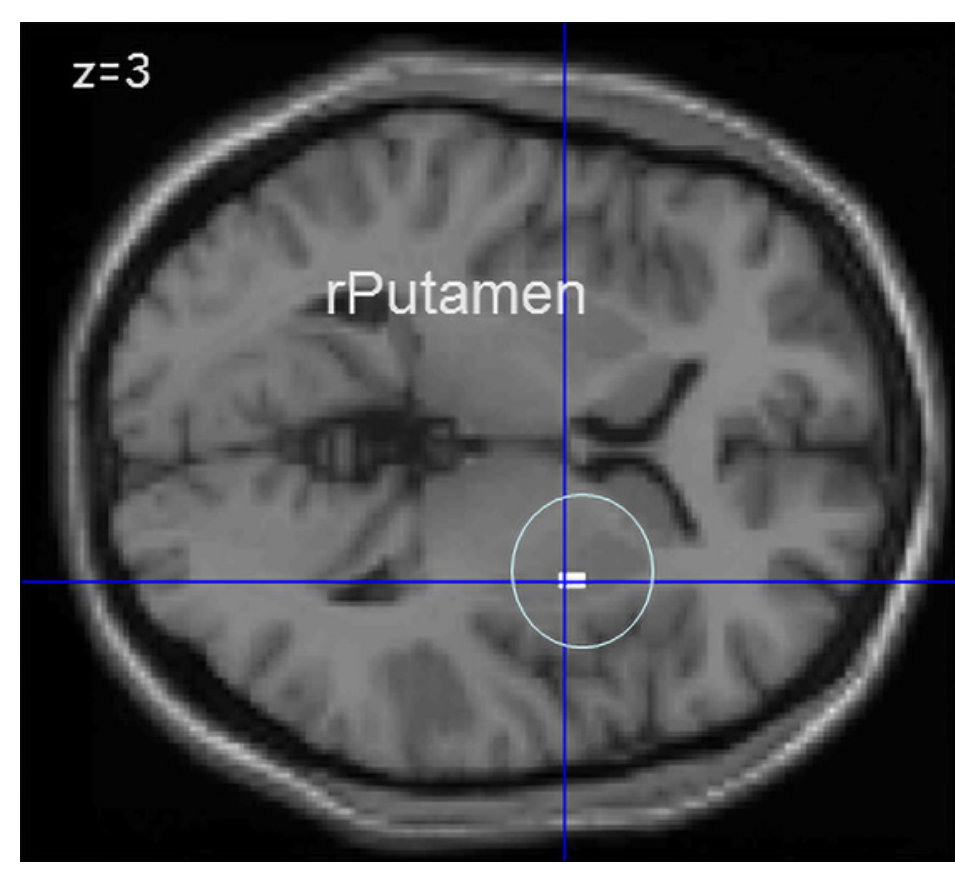

\begin{tabular}{|c|c|c|c|c|}
\hline & \multirow[t]{2}{*}{$t$ value } & \multicolumn{3}{|c|}{ Talairach coordinates } \\
\hline & & $x$ & $y$ & $z$ \\
\hline Putamen & 3.46 & 30 & 0 & 3 \\
\hline Thalamus & 3.46 & -23 & -21 & 12 \\
\hline
\end{tabular}

PAR patients versus HYP patients. $p_{\text {uncorr }}<0.003$, cluster level 3.

activation in the ventral striatum, which is known to be significantly involved in the processing of odor valence [33]. Considering that PAR patients typically perceive unpleasant sensations, and that unpleasant stimuli - in general - produce stronger activation than pleasant stimuli, due to their higher biological significance, it appears logical that PAR patients exhibit this difference with HYP patients [30-32].

While these activations fit well into existing hypotheses, they do not tell much about the source of the parosmic impressions, apart from the idea that the distortion of the odorous information appears to be there very early in the olfactory system as the entire pattern of activation in PAR patients is different from the pattern of activation in HYP patients. Such an early stage of distorted olfactory processing may be at the level of the olfactory epithelium [33] or the olfactory bulb, which has previously been found to be altered in patients with parosmia $[10,11]$.

\section{Conclusion}

These results support the idea that there are distinct differences in the central processing of olfactory stimuli between hyposmic patients with and without parosmia. The results may further be taken to indicate that the brain site causing distortions may be at the very beginning of the processing cascade, e.g., at the level of the olfactory epithelium or the olfactory bulb. 


\begin{tabular}{l|l}
\hline ORL 2019;81:185-192 \\
\hline DOI: 10.1159/000500558 & $\begin{array}{l}\text { (c) 2019 S. Karger AG, Basel } \\
\text { www.karger.com/orl }\end{array}$ \\
\hline
\end{tabular}

lannilli et al.: Parosmia

\section{Acknowledgments}

We are deeply indebted to the work of Benno Schuster and Henrik Eumann during the collection of data. We are also indebted to the help of Johannes Gerber during data acquisition in the MR environment.

\section{Statement of Ethics}

The study was performed according to the Declaration of Helsinki. All participants provided written informed consent.

\section{Disclosure Statement}

None of the authors declares a conflict of interest.

\section{References}

1 Zilstorff ZK. Parosmia. J Laryngol. 1966;80:1102-4.

2 Hummel T, Whitcroft KL, Andrews P, Altundag A, Cinghi C, Costanzo RM, et al. Position paper on olfactory dysfunction. Rhinol Suppl. 2017 Mar;54(26 Suppl. 25):1-30.

3 Kobal G, Hummel T, Sekinger B, Barz S, Roscher S, Wolf S. "Sniffin' sticks”: screening of olfactory performance. Rhinology. 1996 Dec;34(4):222-6.

4 Leopold D. Distorted olfactory perception. In: Doty RL, editor. Handbook of olfaction and gustation. New York: Marcel Dekker, Inc.; 1995. pp. 441-54.

5 Reden J, Maroldt H, Fritz A, Zahnert T, Hummel T. A study on the prognostic significance of qualitative olfactory dysfunction. Eur Arch Otorhinolaryngol. 2007 Feb;264(2):139-44.

6 Hong SC, Holbrook EH, Leopold DA, Hummel T. Distorted olfactory perception: a systematic review. Acta Otolaryngol. 2012 Jun;132(sup1 Suppl 1):S27-31.

7 Rawal S, Hoffman HJ, Bainbridge KE, Huedo-Medina TB, Duffy VB. Prevalence and Risk Factors of Self-Reported Smell and Taste Alterations: Results from the 2011-2012 US National Health and Nutrition Examination Survey (NHANES). Chem Senses. 2016 Jan;41(1):69-76.

8 Leopold DA, Schwob JE, Youngentob SL, Hornung DE, Wright HN, Mozell MM. Successful treatment of phantosmia with preservation of olfaction. Arch Otolaryngol Head Neck Surg. 1991 Dec;117(12):1402-6.

9 Leopold D. Distortion of olfactory perception: diagnosis and treatment. Chem Senses. 2002 Sep;27(7):611-5.

10 Mueller A, Rodewald A, Reden J, Gerber J, von Kummer R, Hummel T. Reduced olfactory bulb volume in posttraumatic and post-infectious olfactory dysfunction. Neuroreport. 2005 Apr;16(5):475-8.

11 Rombaux P, Mouraux A, Bertrand B, Nicolas G, Duprez T, Hummel T. Olfactory function and olfactory bulb volume in patients with postinfectious olfactory loss. Laryngoscope. 2006 Mar;116(3):436-9.

12 Frasnelli J, Landis BN. Heilmann S, et al. Clinical presentation of qualitative olfactory dysfunction. Eur Arch Otorhinolaryngol. 2004 Aug;261(7):411-5.

13 Mori K, Nagao H, Yoshihara Y. The olfactory bulb: coding and processing of odor molecule information. Science. 1999 Oct;286(5440):711-5.

14 Landis BN, Frasnelli J, Croy I, Hummel T. Evaluating the clinical usefulness of structured questions in parosmia assessment. Laryngoscope. 2010 Aug;120(8):1707-13.

15 Welge-Luessen A, Leopold DA, Miwa T. Smell and taste disorders - diagnostic and clinical work-up. In: WelgeLuessen A, Hummel T, editors. Management of smell and taste disorders - a practical guide for clinicians. Stuttgart: Thieme; 2013. pp. 49-57.

16 Hummel T, Sekinger B, Wolf SR, Pauli E, Kobal G. 'Sniffin' sticks': olfactory performance assessed by the combined testing of odor identification, odor discrimination and olfactory threshold. Chem Senses. 1997 Feb; 22(1):39-52.

17 Hummel T, Kobal G, Gudziol H, Mackay-Sim A. Normative data for the "Sniffin' Sticks" including tests of odor identification, odor discrimination, and olfactory thresholds: an upgrade based on a group of more than 3,000 subjects. Eur Arch Otorhinolaryngol. 2007 Mar;264(3):237-43.

18 Talairach J, Tournoux P. Co-planar stereotaxic atlas of the human brain. New York: Thieme; 1988.

19 Gottfried JA, Dolan RJ. Human orbitofrontal cortex mediates extinction learning while accessing conditioned representations of value. Nat Neurosci. 2004 Oct; $7(10): 1144-52$.

20 Pellegrino R, Hähner A, Bojanowski V, Hummel C, Gerber J, Hummel T. Olfactory function in patients with hyposmia compared to healthy subjects - An fMRI study. Rhinology. 2016 Dec;54(4):374-81. 
lannilli et al.: Parosmia

21 Plailly J, Howard JD, Gitelman DR, Gottfried JA. Attention to odor modulates thalamocortical connectivity in the human brain. J Neurosci. 2008 May;28(20):5257-67.

22 Phillips ML, Young AW, Scott SK, Calder AJ, Andrew C, Giampietro V, et al. Neural responses to facial and vocal expressions of fear and disgust. Proc Biol Sci. 1998 Oct;265(1408):1809-17.

23 Thielscher A, Pessoa L. Neural correlates of perceptual choice and decision making during fear-disgust discrimination. J Neurosci. 2007 Mar;27(11):2908-17.

24 Kipps CM, Duggins AJ, McCusker EA, Calder AJ. Disgust and happiness recognition correlate with anteroventral insula and amygdala volume respectively in preclinical Huntington's disease. J Cogn Neurosci. 2007 Jul;19(7): 1206-17.

25 Alexander GE, Crutcher MD. Preparation for movement: neural representations of intended direction in three motor areas of the monkey. J Neurophysiol. 1990 Jul;64(1):133-50.

26 Monchi O, Petrides M, Strafella AP, Worsley KJ, Doyon J. Functional role of the basal ganglia in the planning and execution of actions. Ann Neurol. 2006 Feb;59(2):257-64.

27 Boecker H, Jankowski J, Ditter P, Scheef L. A role of the basal ganglia and midbrain nuclei for initiation of motor sequences. Neuroimage. 2008 Feb;39(3):1356-69.

28 Yoshimi K, Kumada S, Weitemier A, Jo T, Inoue M. Reward-Induced Phasic Dopamine Release in the Monkey Ventral Striatum and Putamen. PLoS One. 2015 Jun;10(6):e0130443.

29 Fjaeldstad A, Fernandes HM, Van Hartevelt TJ, Gleesborg C, Møller A, Ovesen T, et al. Brain fingerprints of olfaction: a novel structural method for assessing olfactory cortical networks in health and disease. Sci Rep. 2017 Feb; 7(1):42534.

30 Alaoui-Ismaïli O, Vernet-Maury E, Dittmar A, Delhomme G, Chanel J. Odor hedonics: connection with emotional response estimated by autonomic parameters. Chem Senses. 1997 Jun;22(3):237-48.

31 Bensafi M, Rouby C, Farget V, Vigouroux M, Holley A. Asymmetry of pleasant vs. unpleasant odor processing during affective judgment in humans. Neurosci Lett. 2002 Aug;328(3):309-13.

32 Bensafi M, Sobel N, Khan RM. Hedonic-specific activity in piriform cortex during odor imagery mimics that during odor perception. J Neurophysiol. 2007 Dec;98(6):3254-62.

33 Holbrook EH, Leopold DA, Schwob JE. Abnormalities of axon growth in human olfactory mucosa. Laryngoscope. 2005 Dec;115(12):2144-54. 